\title{
Peran Guru Madrasah dalam Menanaman Nilai-Nilai Pendidikan Lingkungan Hidup Perspektif Pendidikan Islam (Studi Kasus di Madrasah Aliyah Negeri 7 Keboan Jombang)
}

\author{
Auliyaaurohmah ${ }^{1,}$ Khoirul Umam ${ }^{2}$, \\ ${ }^{1}$ Pendidikan Agama Islam, Fakultas Agama Islam, Universitas Hasyim Asy'ari \\ ${ }^{2}$ Pendidikan Agama Islam, Fakultas Agama Islam, Universitas Hasyim Asy'ari
}

\section{Article Info}

Article history:

Received 2019-10-02

Accepted 2020-02-27

\section{Keywords:}

Pendidikan Lingkungan Hidup, Pendidikan Islam, Peran Guru

\begin{abstract}
The effort to preserve the beauty of the environment is an obligation for every social creature that lives on this earth. These efforts are carried out and planned so that every human being has a caring attitude and responsibility with the surrounding environment. In educational institutions the role of a teacher cannot be separated in the educational process. To realize students as quality resources cannot be separated from the environment. This article intends to explain about environmental education in Madrasah Aliyah Negeri 7 Jombang. With a qualitative case study approach, this research was carried out through observation, interviews and documentation. The results of the discussion from the research show that, in the implementation of their roles and participation in forming and increasing environmental awareness by teachers, students are well implemented. Most of them have a caring attitude to their environment, which is proven by their daily habits, which is to dispose of waste according to the space provided. It's just that for minorities who are still indifferent to the environment, support and encouragement from teachers need to be increased so that all madrasa residents, especially students, have positive behavior, be aware and care about the surrounding environment
\end{abstract}

This is an open access article under the CC BY-SA license.

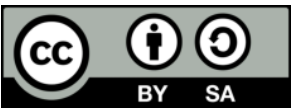

\section{Corresponding Author:}

Auliyaaurohmah, Khoirul Umam

Pendidikan Agama Islam, Fakultas Agama Islam, Universitas Hasyim Asy’ari

Email: aulliya343@gmail.com

\section{PENDAHULUAN}

Manusia yang disebut juga dengan makhluk sosial, hidup di muka bumi diharapkan menjadi manusia yang berkualitas. Upaya peningkatan kualitas sumber daya manusia (SDM) tidak bisa memisahkan diri dengan masalah pendidikan. Salah satunya yaitu pendidikan lingkungan hidup.

Lingkungan hidup sangat mempengaruhi bagaimana kelangsungan hidup manusia, di dalam pendidikan juga mempengaruhi proses pembelajaran. Lingkungan hidup merupakan tempat bagi semua makhluk hidup tinggal dan menjaga kelangsungan hidupnya, termasuk manusia.

Pada konsep ekologi secara umum lingkungan hidup macamnya terbagi menjadi dua bagian yang pertama lingkungan biotik dan yang kedua lingkungan abiotik. Lingkungan biotik yaitu semua organisme hidup disekitar organisme hidup lain yang ada di bumi ini termasuk manusia. Sedangkan lingkungan abiotik yaitu semua unsur yang ada dibumi selain organisme hidup seperti udara, air, dan tanah. (Mukhtashor, 2008:63-64)

Untuk menjaga terjaminnya kelestarian lingkungan hidup, faktor manusia ini adalah sangat dominan, pengaruhnya dapat mengakibatkan dua kemungkinan pada kualitas lingkungan tersebut yaitu rusak atau tetap lestari.

Pendidikan lingkungan hidup atau PLH merupakan usaha sadar yang direncanakan untuk perubahan sikap serta perilaku dengan tujuan supaya masyarakat lebih sadar dan peduli dengan lingkungan hidup 
disekitarnya (Tim MKU PLH Unnes, 2014:2).

Kebijakan pendidikan lingkungan hidup memiliki sasaran yaitu menciptakan kepedulian serta komitmen masyarakat dalam kegiatan perlindungan, pelestarian, dan peningkatan kualitas lingkungan hidup. PLH diarahkan kepada seluruh masyarakat baik yang di desa maupun di kota, tua maupun muda, laki-laki maupun perempuan (Sudjoko,2014:1.17).

Pada dasarnya tujuan pendidikan lingkungan hidup terbagi menjadi 5 menurut Fien yang dikutip oleh Miyake dalam MKU PLH Unnes (2014:5) yaitu bidang pengetahuan membantu menambah bermacammacam pengalaman dan juga pengetahuan guna menjaga lingkungan, pada bidang kesadaran, terbantu pada peningkatan rasa sadar dan peka terhadap lingkungan, bidang perilaku membantu mendapatkan rasa peduli lingkungan dan memotivasi agar individu berpartisipasi aktif dalam perlindungan lingkungan, bidang keterampilan membantu mengidentifikasi, mengantisipasi, mencegah dan melakukan penyelesaian masalah tentang lingkungan, yang terakhir yakni bidang partisipasi yang membatu dalam pemberian kesempatan serta juga motivasi pada individu supaya turut serta secara aktif dalam penciptaan lingkungan hidup yang berkelanjutan.

Oleh karena itu, tujuan akhir pada PLH ialah menciptakan individu yang sadar, peduli dan peka terhadap lingkungan hidup yang ada disekitar mereka. Artinya individu harus memiliki sikap, dan perilaku yang cinta terhadap lingkungan hidupnya.

Seperti halnya dalam Al-Qur'an telah dijelaskan mengenai ayat-ayat yang menerangkan larangan merusak lingkungan, salah satunya yaitu terdapat pada QS. Al-A'raf ayat 56 :

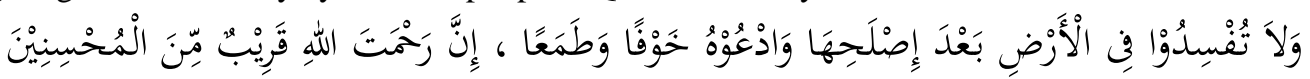

Artinya "Dan janganlah kamu berbuat kerusakan di bumi setelah (diciptakan) dengan baik. Berdoalah kepada-Nya dengan rasa takut dan penuh harap. Sesungguhnya rahmat Allah sangat dekat kepada orang yang berbuat kebaikan." (QS.7:56)

Pada ayat tersebut dijelaskan bahwa setiap manusia memiliki kesadaran dan tanggungjawab atas kualitas lingkungan hidup mereka. Manusia diwajibkan untuk memiliki akhlak yang mulia terhadap lingkungan sekitarnya.

Berdasarkan penjelasan diatas, pendidikan lingkungan hidup memiliki tujuan yang baik seperti halnya dengan tujuan pendidikan Islam.

Menurut Langgulung dalam Muhaimin Istilah untuk pendidikan Islam secara umum mencakup pada tarbiyatul diniyah, ta'limud din, ta'limud diny, ta'limul Islamy, tarbiyatul muslimin, tarbiyah fil Islam, tarbiyah 'indal muslimin, tarbiyatul Islamiyah. (Muhaimin, 2012: 38)

Menurut Al-Syaibani dalam Muchsin (2010:5) Pendidikan Islam memiliki arti usaha melalui proses pendidikan guna mengubah perilaku individu dalam kehidupanya secara pribadi maupun kehidupan di masyarakat dan kehidupan di alam sekitarnya.

Tujuan dari pendidikan Islam secara umum yaitu dihasilkannya individu yang bermanfaat bagi dirinya sendiri, masyarakat, serta ia bahagia dalam mengamalkan, mengembangkan dan menyebarkan agama Islam. Dalam hubungannya dengan Allah, individu dengan sesamanya juga dapat mengambil mafaat yang semakin meningkat dari alam semesta ini untuk kepentingan hidup di dunia dan di akhirat.

Pendidikan lingkungan hidup berhubungan dengan nilai-nilai terkait dengan sikap, dan tindakan positif untuk lingkungan (Muhaimin,2015:25).

Nilai sendiri memiliki arti sebagai sebuah perangkat yang digunakan untuk menghasilkan alasan dasar bahwa langkah-langkah pelaksanaan kegiatan yang ditentukan atau keadaan akhir yang juga telah ditentukan seringkali disukai oleh individu secara sosial dibandingkan dengan pelaksanaan atau keadaan yang akhir yang berlawanan atau tidak ditentukan.

Nilai sendiri memuat beberapa pertimbangan yang mengangkat ide-ide seseorang pada banyak hal yang dianggap benar, apik, maupun diinginkan. (id.wikipedia.org/Wiki/Nilai)

Nilai-nilai yang terkandung dalam pendidikan lingkungan hidup terkait akhlak, baik perkataan, perbuatan maupun tindakan sebagaimana pada tujuan pendidikan Islam yakni mengajarkan untuk cinta dan peduli terhadap lingkungan. Beberapa kegiatan atau tindakan yang dapat terlaksana dalam pendidikan lingkungan hidup yang dipandang menurut perspektif Islam diantaranya yaitu : Penghijauan, menjaga kebersihan, melindungi satwa, dan membatasi penggunaan air.

Pelestarian lingkungan dalam agama Islam yaitu memberikan perhatian yang cukup terkait penghijauan dengan cara menanam. Hal tersebut telah dijelaskan dalam sebuah hadits Rasulullah saw:

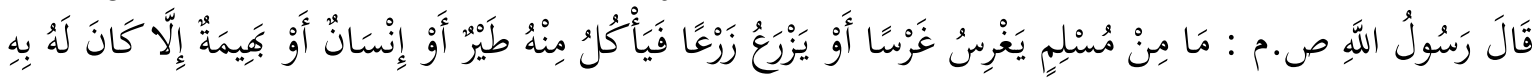

Artinya: "tidaklah seorang muslim menanam tanaman, kemudian tanaman itu dimakan oleh burung, 
manusia, ataupun hewan, kecuali baginya dengan tanaman itu adalah sadaqah".(Shahih Bukhari:1992, 390)

Slogan yang sering kali didengar tentang ajakan, nasihat yang mengingatkan pada individu supaya tetap menjaga kebersihan, salah satunya ada pada kalimat "bersih pangkal sehat atau kebersihan adalah sebagian daripada iman", hal ini tersirat betapa harusnya menjaga kebersihan bagi setiap manusia agar terjaga kesehatannya, baik individu sendiri, keluarganya, masyarakat, maupun lingkungan sekitar.

Kebersihan merupakan perihal atau keadaan bersih, yang suci, murni, tulen, dan keadaan yang dipercaya, diyakini oleh akal, dan pengetahuan seseorang yang dianggap tidak mengandung noda atau kotoran. (KBBI, 142)

Kebersihan juga diterangkan dalam salah satu hadits riwayat tirmidzi yang artinya: Rasulullah SAW, Beliau bersabda:

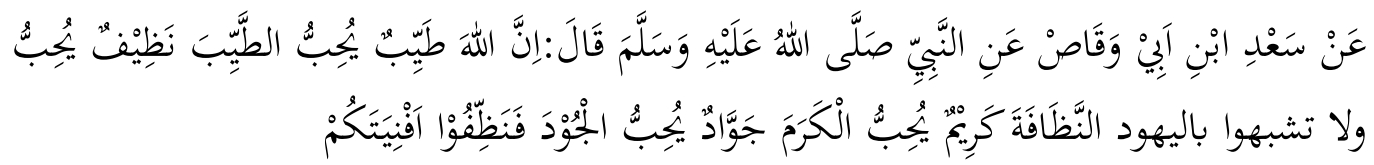

Artinya : "Sesungguhnya Allah baik, menyukai kebaikan. Dia Maha Bersih, menyukai kebersihan. Maha Mulia, menyukai kemuliaan. Maha Dermawan , menyukai kedermawanan. Karena itu bersihkanlah halaman rumahmu dan jangan meniru-niru orang-orang Yahudi." (Sunan Tirmidzi: 1994,365).

Kebersihan diupayakan oleh setiap individu guna merawat diri dan lingkungan sekitar dari bermacammacam kotoran, baik secara lahiriyah maupun batiniyah. Kotor pada badan atau yang bersifat lahiriyah dapat disucikan dengan banyak langkah bersuci yang baik misalnya mandi, memotong kuku, dan lain-lain.

Adapun kotor yang bersifat batiniyah semisal penyakit pada hati mulai dari riya', takabbur, hasud, syirik, dan lain sebagainya dapat disucikan dengan memohon ampunan dan taubat kepada Allah swt. Apabila taubat diterima Allah swt. hasilnya akanlah bersih dosa-dosa pada diri individu. Teramat pentingnya menjaga kebersihan, kesucian dan amat mahalnya kesehatan bagi manusia, sehingga Allah swt. yang tidak segan memberikan cintanya kepada individu yang selalu memohon ampunan dan merawat lingunkan supaya terjaga kebersihannya, seperti dalam Firman-Nya:

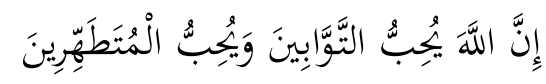

Artinya: Sungguh, Allah menyukai orang-orang yang bertaubat dan menyukai orang-orang yang bersuci. (QS. 2: 222)

Membatasi penggunaan air atau sering juga tersebut dalam kegiatan menghemat energi perlu sekali untuk dilakukan. Pada hakikatnya air adalah sumber kehidupan baik bagi manusia maupun makhluk hidup yang lainnya.

Tuhan pencipta alam semesta ini telah menyediakan air laut, air sungai serta air hujan secara gratis, seringkali manusia tidak menggunakan dan memanfaatkan air sebagaimana mestinya. Sesuatu penting patut dan perlu direnungkan ialah adanya air bukanlah sumber daya alam yang dapat berkembang, hal tersebut tidak sama dengan kekayaan alam yang lainnya, karena itu Allah swt, memerintahkan makhluknya utamanya manusia wajib menjaga dan melestarikan keberadaan air.

Pendidikan lingkungan hidup formal merupakan kegiatan pendidikan pada bidang lingkungan hidup yang dipraktikkan melalui madrasah baik pada jenjang dasar, menengan maupun pendidikan tinggi, pelaksanaannya terstruktur dan bertahap dengan metode pendekatan kurikulum terintegrasikan maupun yang monolitik. (Sudjoko: 1.16)

Pendidikan lingkungan hidup terlaksana di Madrasah Aliyah Negeri 7 Jombang dengan dengan bentuk program adiwiyata. Namun, Madrasah ini belum menjadi madrasah dengan predikat adiwiyata baik propinsi, nasional ataupun mandiri. MAN 7 jombang sedang dalam proses menuju adiwiyata provinsi.

Program tersebut dimulai tahun 2015-2016, terencna mengikuti penilaian untuk adiwiyata provinsi pada tahun 2018 dan belum berhasil yang disebabkan karena masih terdapat hal yang kurang dan tahun 2019 mengajukan kembali untuk mendapatkan predikat madrasah adiwiyata tingkat provinsi.

Kegiatan-kegiatan untuk mensukseskan adiwiyata di MAN 7 Jombang dalam pelaksanaannya harus didukung oleh sarana dan prasarananya sesuai dengan kebutuhan agar dapat berjalan dengan baik. Program ini membutuhkan partisipasi dari seluruh warga MAN 7 Jombang, terutama kepala madrasah, seluruh dewan guru dan seluruh peserta didik.

Menurut Suprihatiningrum (2016:23) secara garis besar, guru dikenal dalam bahasa Arab al-mu'alim, atau al-ustadz yang berarti seseorang yang memberi ilmu. Adapun pada KBBI guru merupakan orang yang memiliki pekerjaan maupun mata pencaharian maupun profesi sebagai pengajar.

Peran penting guru dalam pelaksanaan pendidikan terutama pembelajaran tidak dapat terlepas begitu saja. Pengertian peran memiliki arti sebagai pemain atau sesuatu yang menjadi bagian atau yang memegang 
pimpinan yang utama dalam suatu peristiwa. (Kamus Lengkap Bahasa Indonesia Modern).

Peran guru sebagaimana dijelaskan oleh Sanjaya (2006:20) ada 7, diantaranya guru menjadi sumber belajar, fasilitator, pengelola, demonstrator, pembimbing, motivator dan evaluator.

Proses belajar tidak hanya dilakukan di kelas saja. Pembelajaran tentang kesadaran akan kepedulian dan mencintai lingkungan dapat dimulai dari para dewan guru yang menjadi figur yang dicontoh dan ditiru peserta didiknya. Hal itu termasuk guru telah melaksanakan perannya sebagai demonstrator.

Penelitian ini dimaksudkan untuk mengkaji dan menganalisis peran guru di Madrasah Aliyah Negeri 7 Jombang dalam penanaman nilai-nilai pendidikan lingkungan hidup. Untuk itu masalah yang akan di bahas adalah bagaimana peran guru dalam proses dan peningkatan dari penanaman nilai-nilai pendidikan lingkungan hidup perspektif pendidikan Islam, serta faktor yang menajdi pendukung dan penghambat dalam kegiatan tersebut di MAN 7 Jombang.

\section{METODE}

Penelitian ini adalah penelitian kualitatif dimana menekankan pada hal tertentu dan penting dari sesuatu baik berupa kejadian, fenomena ataupun gejala sosial (Satori, 2017:2). Peneliti menggunakan jenis studi kasus memiliki arti yaitu suatu kajian yang rinci tentang latar, subjek tunggal, tempat penyimpanan dokumen, ataupun peristiwa tertentu. (Bogdan dan Biklen yang dikutip oleh Rulam (2016:9))

Oleh karena itu, penelitian ini mengkaji tentang peran guru dalam menanamkan nilai-nilai pendidikan lingkungan hidup di Madrasah Aliyah negeri 7 Jombang.

Data yang diperoleh merupakan data kualitatif, karena data tidak disajikan dalam bentuk angka, melainkan dalam bentuk deskripsi kalimat. Sumber data dalam penelitian ini yaitu kepala madrasah, waka kesiswaan, ketua tim adiwiyata MAN 7 Jombang, pembimbing pokja KLH, guru BK, dan peserta didik. Pengumpulan data melalui teknik pengamatan, wawancara serta dokumentasi.

Adapun uji keabsahan data menggunakan uji kredibilitas, yang mana dilakukan melalui triangulasi yaitu membuktikan bahwa temuan peneliti tentang pelaksanaan peran oleh guru dalam menanamkan nilainilai pendidikan lingkungan hidup di MAN 7 Jombang sesuai dengan fakta yang terlaksana di lapangan dan juga mempertajam tilikan terhadap sejumlah data yang diperoleh.

\section{HASIL DAN PEMBAHASAN}

Pendidikan lingkungan hidup terlaksana di MAN 7 Jombang dapat dikatakan oleh karena tuntutan yang harus diwujudkan. Selain karena dalam agama Islam mengajarkan untuk hidup bersih yang dimulai dari bersuci, sebagai sekolah berbasis agama Islam, MAN 7 mengikuti program adiwiyata untuk penghargaan tingkat Jawa Timur. Program adiwiyata di MAN 7 memiliki berbagai kegiatan, salah satunya adalah menjaga lingkungan agar terbebas dari sampah. Artinya, seluruh warga sekolah diharuskan untuk memilih dan memilah sampah untuk dibuang pada tempat yang telah disediakan, baik itu sampah organik maupun anorganik.

Dalam pelaksanaannya peran serta dari warga madrasah sangatlah penting, terutama guru. Karena guru dapat dikatakan juga sebagai orang tua di lingkungan sekolah yang mendidik, membimbing juga memberikan arahan agar peserta didik mengembangkan potensi yang dimilikinya.

Kepala Madrasah selalu menghimbau agar peserta didik dan guru selalu peduli dengan lingkungan sekitar madrasah agar selalu tetap bersih dan terjaga keasriannya dan juga untuk mewujudkan madrasah adiwiyata tingkat provinsi. Himbauan agar selalu peduli dengan lingkungan dilakukan setiap apel pagi di hari senin maupun ketika rapat dewan guru (kepala madrasah, 2/3/19).

Peran guru sebagaimana tertera pada bagian pendahuluan, tidak dapat terpisah pada pelaksanaan pendidikan lingkungan hidup yang bertujuan agar individu memiliki sikap dan tanggungjawab menjaga dan melestarikan lingkungan.

Dalam pendidikan lingkungan hidup sebagai sumber belajar, peserta didik diberikan wawasan dan juga materi tentang lingkungan hidup baik yang disinggung dalam pembelajaran di kelas maupun di luar kelas.

Sebagai fasilitator, guru menyediakan sarana penunjang untuk terlaksananya program adiwiyata seperti alat-alat kebersihan, mengadakan pelatihan untuk peserta didik yang terdaftar dalam kelompok kerja KLH dalam hal pengelolaan sampah maupun komposting.

Guru sebagai pengelola, mengadakan kegiatan kerja bakti madrasah secara rutin dalam satu bulan sekali, juga dalam memperingati hari sampah, hari bumi.

Sebagai demonstrator, guru memberikan contoh tindakan yang selanjutnya ditiru oleh peserta didiknya. Seperti halnya tindakan kecil yakni jika ada sampah yang tidak pada tempatnya dibuang pada tempat yang telah ditentukan. Mematikan kran air jika bak di dalam kamar mandi telah penuh. Tetapi dalam pelaksanaannya masih terdapat beberapa individu yang bisa dikatakan minim pengetahuan tentang menjaga lingkungan terutama pada poin-poin yang tertera pada adiwiyata yakni sampah, energi, air, dan keanekaragaman hayati.(wawancara ketua tim adiwiyata MAN 7)

Tujuan dari penanaman nilai-nilai pendidikan lingkungan hidup ialah misi dalam upaya mendewasakan 
diri, dalam hal ini harapan besarnya yaitu supaya peserta didik bertingkah laku alami, serta bertanggung jawab akan lingkungan hidup disekitarnya. sesuai dengan tujuan tersebut guru memberikan bimbingan dan arahan pada peserta didik dalam pemecahan masalah yang dihadapi. Masing-masing individu diharapkan memiliki semangat untuk belajar dan berperilaku yang baik terkait kepeduliannya terhadap lingkungan hidup di madrasah, terutama guru. Hal tersebut harus jelas adanya sebab guru yang semangat dapat mempengaruhi peserta didiknya, dengan kata lain peserta didik termotivasi, terdorong untuk melakukan perubahan kearah positif untuk mewujudkan madrasah yang memiliki suasana sejuk, nyaman dan indah. Seperti memberikan penghargaan atau reward pada setiap kelas yang mendapatkan juara pada lomba kelas terbersih.

Terlaksananya program adiwiyata di MAN 7 Jombang didukung oleh landasan ideologis An Nadlofatu Min Al Iman yang berarti bahwa kebersihan itu merupakan hal yang pokok, faktor berikutnya yaitu tugas manusia sebagai khalifah di bumi menjadi penyemangat, karena MAN 7 ini basicnya Islam mayoritas sudah faham tentang kultur bersih yang dijelaskan di dalam Islam, dan kemauan dari komite, dewan guru, wali murid dan masyarakat sekitar madrasah mengadakan semacam gerakan peduli bumi, sampah, dan melakukan kerja sama dengan perhutani dan PT. Chiel Jedang Indonesia. (Kepala Madrasah, 2/3/19)

Dalam melaksanakan tugas sebagai guru di Madrasah yang menuju adiwiyata, ada beberapa guru yang memberikan tugas ketika pembelajaran sudah memanfaatkan teknologi yang sudah maju ini dan tidak menggunakan kertas-kertas, dengan tujuan meminmalisir sampah yang dihasilkan.

Terkait dengan peranannya yang telah dijelaskan, melaksakan tugas seperti itu sudah banyak, hanya saja masih ada beberapa yang terkesan acuh tak acuh jika melihat sampah yang terlihat di depan kelas maupun tempat lain di lingkungan madrasah. Hambatan yang seperti itu disebut sebagai hambatan intern yang terletak pada masing-masing individu yang menjadi warga madrasah. Mereka masih memiliki pemikiran bahwa hidup bersih itu bukan sesuatu yang harus dilakukan dan kurang membantu dalam mewujudkan madrasah berpenghargaan adiwiyata.

Pada MAN 7 Jombang, PLH pernah menjadi mata pelajaran yang berdiri sendiri atau dapat diartikan masuk pada kurikulum, untuk masa sekarang sudah tidak dimasukkan dalam kurikulum lagi karena perubahan simpatika, tetapi bentuknya dilaksanakan pada program adiwiyata yang di dalam program tersebut terdapat ekstrakurikuler KLH (Kader Lingkungan Hidup).

\section{KESIMPULAN}

Sebagaimana pendahuluan dan pembahasan terkait peran guru dan pendidikan lingkungan hidup yang telah terpaparkan diatas, di MAN 7 Jombang telah dilakukan secara maksimal, karena mereka memberikan wawasan, bimbingan, fasilitas dan motivasi sehingga peserta didik mayoritas telah memiliki tingkah laku yang positif sesuai dengan ajaran agama Islam serta kesadaran dan rasa peduli dengan lingkungan hidup. Hal ini dibuktikan dengan kebiasaan peserta didik untuk rutin melakukan piket kelas dan dalam memilah sampah.

Faktor pendukung dalam penanaman nilai-nilai pendidikan lingkungan hidup perspektif pendidikan Islam yaitu terletak pada motivasi diri dan kerja sama antara pihak MAN 7 dengan berbagai instansi lain. Sedangkan faktor penghambatnya ada pada beberapa individu yang masih kurang kesadaran diri, sikap peduli dan masa bodoh dengan lingkungan sekitarnya.

\section{REFERENSI}

Ahmadi, Rulam. 2016. Metodologi Penelitian Kualitatif. Yogyakarta: Ar-Ruzz Media.

Al Bukhari, Abu Abdillah Muhammad bin Ismail. Shahih Bukhari. 1992. Terj. Achmad Sunarto. Cet. I. Semarang: Asy Syifa'.

At-Tirmidzi, Abu Isa Muhammad bin Isa bin Saurah. Sunan at-Tirmidzi. 1994. Juz 4. Beirut: Dar al-Fikr.

Bashori Muchsin, dkk. 2010. Pendidikan Islam Humanistik Alternatif Pendidikan Pembebasan Anak. Bandung: Refika Aditama.

Muhaimin. 2015. Membangun Kecerdasan Ekologis. Bandung: Alfabeta.

Sanjaya, Wina. 2006. Strategi Pembelajaran Berorientasi Standar Proses Pendidikan, Jakarta: Kencana.

Satori, Djam'an. 2017. Metodologi Penelitian Kualitatif,. Bandung: Alfabeta.

Suaedi dan Hammado Tantu. 2016. Pembelajaran Pendidikan Lingkungan Hidup. Bogor: IPB Press.

Sudjoko, dkk. 2014. Pendidikan Lingkungan Hidup, Tangerang Selatan: Universitas Terbuka.

Tim MKU PLH. 2014. Buku Ajar Pendidikan Lingkungan Hidup. Universitas Negeri Semarang.

Undang-Undang Republik Indonesia Tentang SISDIKNAS 